peutic community' approach, group therapy, the use of social workers as group therapists, tc. - has been practised in alcoholic units in Britain with success for the same period, and is the basis of the management of regional alcoholic units now recommended by the Ministry of Health. It is therefore clear that the author's findings, discussions and conclusions also are of great relevance and interest to Britain. He has certainly succeeded in his aim of studying closely the part which addiction plays in the lives of a limited number of alcoholics; and, by the presentation of data in what he calls a qualitative rather than a quantitative form, and the adoption and description of the life-history approach, he gives the reader many fascinating glimpses into the lives, individual problems and worries of alcoholics. At the same time, he is careful not to draw too far-reaching conclusions and to point out the limitations which are inevitable when studying samples of such a diversified population as formed by alcoholics. Alcoholism is a very complex subject requiring a multi-dimensional interdisciplinary approach. Anyone whose work brings him in contact with alcoholics or who is concerned with alcohol problems in general will find close study of Dr. Jones's Alcoholic Addiction: A Psycho-social Approach to Abnormal Drinking extremely interesting and highly rewarding.

M. M. GLatT

\section{TWENTY YEARS OF VITAMINS AND HORMONES}

\section{Vitamins and Hormones}

Advances in Research and Application. Vol. 20. Edited by Robert S. Harris and Ira G. Wool: Consulting Editors: G. F. Marrian and Kenneth V. Thimann. Pp. xvii + 707. (New York and London: Academic Press Inc., 1962.) 114s. $6 d$.

WTTH this, the twentieth volume, Vitamins and Hormones celebrates twenty years of continuous publication, and the editors have appropriately invited P. Karrer and G. Pincus to mark tho occasion by writing guest prefaces in which they express their appreciation of the service this publication has given to all of us working in the field. The past twenty years cover a period of extraordinary growth and development both in vitamin research and in endocrinology, and there can be little doubt that the many authoritative reviews published in Vitamins and Hormones have made a valuable contribution to progress, both through their critical assessment and clarification of the available information on a topic, and in providing the stimulus for further investigation.

The present volume fully maintains the standards of its predecessors, and it follows the example set two years ago and is enlarged to contain the papers contributed to the symposium on "Vitamin $\mathbf{E}$ and Metabolism" held in honour of H. M. Evans at Zurich in June 1.962. This collection of some twenty papers and discussion by many of the leading workers on vitamin $\mathbf{E}$ gives a comprehensive picture of present-day knowledge of this vitamin. A felicitous account of its early history by H. M. Evans is followed by descriptions by members of the research staff of Hoffmann-La Roche of the chemistry, physico-chemical properties and assay of the tocopherols, and of the absorption and distribution in tissues of the vitamin. Probable steps in the metabolic degradation of $\alpha$-tocopherol are described by C. Martins. R. S. Harris has prepared a valuable summary of the influences of storage and processing on the content of vitamin $\mathrm{E}$ in foods. He emphasizes that much of the published data must be considered to be qualitative, or at best semi. quantitative, for it is only recently that precise methods of analysis have bocome available.
The metabolic function of vitamin $\mathrm{E}$ is considered in detail. K. Schwarz discusses the interrelationships between vitamin $\mathrm{E}$, trace elements and sulphydryl groups in the respiratory decline characteristic of liver tissue from vitamin E-deficient animals during the early stages of diet-induced liver necrosis; J. Green considers the mutual interactions of vitamin $\mathrm{E}$ and other vitamins and the ubiquinones; A. L. Tappel reviews some of the more recent work on the biological function of vitamin $\mathrm{E}$ and of selenium compounds as lipid antioxidants; J.S. Dinning summarizes the findings from his own laboratory on the influence of vitamin $\mathrm{E}$ deficiency on nucleic acid metabolism; H. Dam considers the relationships between vitamin $\mathbf{E}$ and poly-unsaturated fatty acids in experimental animals; M. K. Horwitt describes the longterm experiments he is carrying out with his colleagues on the tocopherol requirements of men and animals; H. M. Nitowsky, K. S. Hsu and H. H. Gordon discuss the vitamin $E$ requirements of human infants; and J. Marks presents a critical evaluation of the therapeutic value of $\alpha$-tocopherol in various disorders. The three remaining articles deal authoritatively with the probable metabolic functions of vitamin $\mathbf{E}$ in farm animals: poultry by M. L. Scott, cattle and sheep by K. L. Blaxter, and pigs by $O$. Swahn and B. Thafvelin. Nevertheless, neither E. C. Slater and P. György, who contribute their comments on the other papers, nor any of the authors of these papers, claim yet to see the solution of the problem of the mechanism of action of vitamin $\mathbf{E}$, and the complexities of its interrelationships with selenium and unsaturated fats.

Six chapters are devoted to hormonal problems: A. I. Winegrad considers the effects of hormones on the metabolism of adipose tissue, with particular reference to the use of in vitro techniques for the investigation of the effects of hormones on glucose utilization, on the synthesis of fatty acids and triglycerides and on the release of free fatty acids by adipose tissue; P. J. Randle and H. E. Morgan contribute a comprehensive review of studies of hormonal and other factors which regulate the uptake of glucose by muscle; D. E. Tapley and W. B. Hatfield discuss present views of the mode of action of thyroxine; $H$. Breuer considers the biosynthesis, intermediary metabolism, conjugation and degradation of natural œestrogens of animal origin; A. D. Lerner and T. H. Lee contribute a short account of the studies leading to the isolation and determination of the structure of the peptides that function as melanocyte-stimulating hormones, and J. P. Mascaren and L. Machlis discuss the probability that hormonal control contributes to the directional growth of pollen tubes.

Two chapters deal with vitamins other than tocopherol: L. J. Reed gives a comprehensive account of lipoic acid and of its biological function as a prosthetic group in $\alpha$-keto-acid dehydrogenase systems in animal and bacterial cells, and discusses possible other roles for this growth factor; T. B. Morgan and J. Yudkin contribute an excellent discussion of the intriguing phenomenon of the vitamin-sparing action of dietary carbohydrates. Their own studies with sorbitol have done much to clarify the situation, and it is now evident that coprophagy supplies the vitamins spared not only with sorbitol and ascorbic acid-containing diets, but also with starchcontaining diets. Thus coprophagy provides the explanation of the condition of refection in rats fed on diets containing high levels of potato or rice starch.

In the remaining chapter, J. E. Kirk spans the fields of both vitamins and hormones in making a useful compilation of the available information on the content of these substances in the tissues of man and animals of various ages.

It is thus abundantly clear that this volume of Vitamins and Hormones worthily upholds its own high standards. May succeeding volumes continue to do so.

J. W. G. Porter 